\title{
Effect of anoxia on the vertical migration of benthic foraminifera
}

\author{
I. A. P. Duijnstee ${ }^{1,2, *}$, S. R. Ernst ${ }^{1,2}$, G. J. van der Zwaan ${ }^{1,2}$ \\ ${ }^{1}$ Department of Geology, Institute of Earth Sciences, Utrecht University, Budapestlaan 4, 3584 CD Utrecht, The Netherlands \\ ${ }^{2}$ Department of Biogeology, Faculty of Sciences, University of Nijmegen, Toernooiveld 1, 6525 ED Nijmegen, The Netherlands
}

\begin{abstract}
We present the results of a microcosm experiment in which benthic foraminifera had to re-establish microhabitat distributions under simulated anoxic and oxygenated bottom-water conditions after initial homogenization of the sediment (obtained from the northern Adriatic Sea at $32 \mathrm{~m}$ water depth). After $3 \mathrm{wk}$, the vertical distribution of the 12 most abundant species was assessed. These taxa could be divided into 2 distinct groups: (1) typical shallow-living species with maximum abundances in the top $2 \mathrm{~cm}$ of the sediment; and (2) deeper-dwelling taxa that were more homogeneously distributed throughout the sediment column. Compared to the oxygenated environment, the average living depth of all species was less under anoxic bottom-water conditions in which the group of shallow dwellers was almost restricted to the top $5 \mathrm{~mm}$ of the sediment. This distribution was most probably caused by negative geotaxis, induced by an external stimulus associated with anoxic conditions (e.g. high $\left[\mathrm{H}_{2} \mathrm{~S}\right]$ ). The deeper-living taxa apparently lack the ability for negative geotaxis or are less sensitive to the stimulus.
\end{abstract}

KEY WORDS: Living benthic foraminifera - Vertical distribution - Vertical migration $\cdot$ Anoxia · Negative geotaxis $\cdot$ Microcosm experiment

Resale or republication not permitted without written consent of the publisher

\section{INTRODUCTION}

Benthic foraminifera are unicellular organisms that are present in great quantities in most marine sediments. Their calcareous tests have an excellent chance of being preserved in the fossil record. Because of this, their fossils can be used as tools for paleoenvironmental reconstructions in the marine realm (see Van der Zwaan et al. 1999 for an overview). To improve the reliability of such reconstructions, it is imperative to gain more insight into the ecology of foraminiferal species. An important aspect of the ecology of benthic foraminifera is their life position within the sediment. Over the past decades, a considerable portion of research has therefore been concentrated on the assessment of the microhabitat preferences of foraminiferal species (e.g. Richter 1961, Buzas 1965, Buzas et al. 1993, Corliss 1985, Linke \& Lutze 1993). Mackensen \& Douglas (1989) pointed out that these studies are important from a taphonomical viewpoint. They stressed that paleoenvironmental interpretations should not be

*Email: iduijn@geo.uu.nl based on the foraminiferal thanatocoenosis (i.e. the fossil assemblage), but on the reconstructed biocoenosis (i.e. the former living community). The thanatocoenosis could be biased by the fact that the chance of preservation of calcareous foraminiferal tests also depends on their position within the sediment (i.e. a higher loss in the more bioturbated interval near the surface). Furthermore, for paleoecological studies involving carbon isotope composition of foraminiferal tests, it is necessary to know more about the microhabitat preferences of the taxa, as their $\delta^{13} \mathrm{C}$ values are influenced by their living depth (Woodruff et al. 1980, Grossman 1984a,b, McCorkle et al. 1990, Jorissen et al. 1995).

Many studies have focused on grouping foraminiferal species with regard to their microhabitat preference. At first, foraminifera were considered to occupy only the sediment surface and the top centimeters of the sediment, but later they were found also to inhabit deeper sediment layers (see Jorissen 1999 for an overview). Subsequently, benthic foraminiferal taxa were 
divided into 2 groups: epifauna and infauna (e.g. Corliss 1985). Strangely, the term epifaunal was generally used as 'not quite so infaunal', also referred to as semi-infaunal (e.g. Murray 1991). Since the dynamic foraminiferal distribution patterns did not fit this simple classification system, refinements were necessary. Some infaunal species were renamed 'predominantly infaunal'; several epifaunal taxa proved to be also 'potentially infaunal' (Barmawidjaja et al. 1992). Linke \& Lutze (1993) suggested that the flexible vertical distribution of foraminifera could not be defined by some static concept, but should be regarded as a dynamic adaptation to optimize food acquisition. This view resulted in a more ecological approach for describing foraminiferal microhabitats, such as the TROX model by Jorissen et al. (1995) and the TROX-2 model by Van der Zwaan et al. (1999).

The northern Adriatic Sea is a highly unstable environment for benthic foraminifera because seasonal stratification and high export of organic matter to the sea floor cause periodic bottom-water dysoxia or even anoxia (Justić 1987, 1991, Degobbis 1989, Van der Zwaan \& Jorissen 1991). Barmawidjaja et al. (1992) suggested that the vertical distribution of the foraminifera in this dynamic setting varied accordingly. They concluded that the changes in vertical foraminiferal distribution were somehow related to bottom-water oxygenation. In an attempt to shed some light on the mechanisms that are responsible for these variations in foraminiferan vertical distribution, we conducted a microcosm experiment with sediment from the northern Adriatic Sea, in which foraminifera had to reestablish microhabitat distributions under anoxic and oxygenated conditions, respectively. We hypothesize that after $3 \mathrm{wk}$ the foraminiferal species' vertical distributions will be different for both treatments. We suggest that in an anoxic environment foraminifera will reside much shallower than during oxygenated bottom-water conditions. We also expected that there would be clear differences in response among different species in the experiment as some species may be adapted to (temporary) anoxia.

\section{MATERIAL AND METHODS}

Material collection and analysis. In January 1998, sediment with live foraminifera was retrieved (using a Van Veen grabber) from the northern Adriatic Sea, at $32 \mathrm{~m}$ water depth, in the muddy sediment belt just southeast of the Po delta $\left(44^{\circ} 45.5^{\prime} \mathrm{N}, 12^{\circ} 45^{\prime} \mathrm{E}\right)$. The top few $\mathrm{cm}$ of the sediment was transported to The Netherlands in 11 polyethylene jars $(1 / 2$ filled with sediment and $1 / 2$ with seawater) at ambient temperature $\left(12^{\circ} \mathrm{C}\right)$. Here, it was sieved with seawater over a $0.5 \mathrm{~mm}$ screen to eliminate the potentially disturbing effects of the few larger bioturbators. After gentle but thorough mixing, the sediment-seawater mixture was poured out into a large open tray and carefully stirred again. As soon as the sediment had settled, a plastic grid was pushed into the sediment, dividing the sediment in 24 equal volumes. Five of these aliquots were randomly selected and emptied using a large syringe to fill 1 U-shaped microcosm (Fig. 1a). This was repeated 3 more times. The remaining 4 sediment volumes in the tray were emptied and stored in 1 jar with ethanol and $1 \mathrm{~g} \mathrm{l}^{-1}$ rose bengal (RB). This material was used to determine species abundances at the beginning of the experiment. The microcosms were incubated in an aerated 641 aquarium, containing seawater (salinity: $37.8 \%$ ) that was collected near the sediment-water interface (using a 301 Niskin bottle) at the sediment sampling site. This aquarium was placed in a dark, climate-controlled room at $16^{\circ} \mathrm{C}$ with a humidity of $100 \%$ (to prevent evaporation). One of the 2 openings of each microcosm was sealed with a rubber stopper in order to prevent gas exchange between this branch and the overlying water.

The oxygen content of the water was monitored continuously using a YSI 5718 oxygen electrode with YSI 5776 membrane, connected to an oxygen meter (YSI

a.

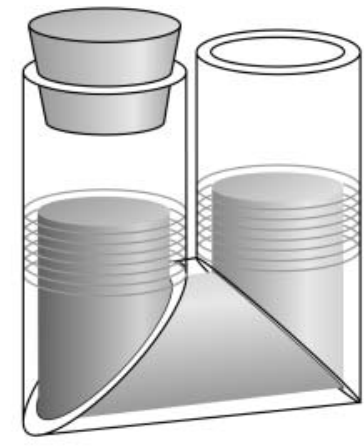

b.

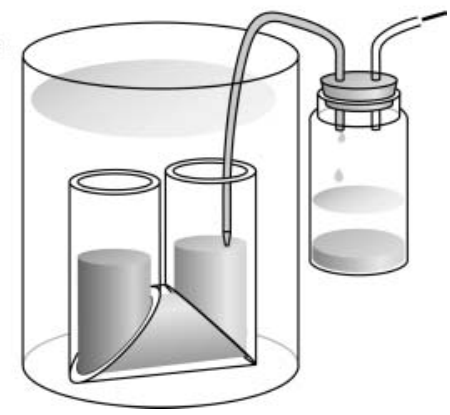

Fig. 1. (a) U-shaped microcosm. The surface area of each of the 2 branches is $25.6 \mathrm{~cm}^{2}$. Lines on the vertical branches of the microcosm indicate $5 \mathrm{~mm}$ depth intervals. (b) Harvesting of the consecutive sediment layers was achieved by carefully sucking up sediment with water into separate jars 
58). In 1 microcosm, the sealed branch was equipped with a similar oxygen electrode. In the other branch, oxygen concentrations just above and within the sediment were measured weekly with oxygen needle electrodes (Microscale Measurements, $\varnothing=1 \mathrm{~mm}$ ) with an $\mathrm{Ag} / \mathrm{AgCl}$ reference electrode (Philips R11-D-SC) and nanoAmp-meter (EDB-RUG MB05 NA).

After $3 \mathrm{wk}$, the sediment in both the sealed and the open branches of all 4 microcosms was harvested in six $5 \mathrm{~mm}$ intervals as shown in Fig. 1. These 48 samples plus the sediment from the lower horizontal part of each microcosm were preserved in ethanol with $1 \mathrm{~g} \mathrm{l}^{-1}$ $\mathrm{RB}$. The RB stains protoplasm remains in the foraminiferal tests. This staining technique is used to distinguish foraminifera that were living at the moment of harvesting from dead ones (Walton 1952).

Finally, all samples were wet sieved over a $63 \mu \mathrm{m}$ screen and the $>63 \mu \mathrm{m}$ material was freeze dried and stored dry until it was microscopically examined. The freeze-dried samples can be stored a very long time, without loss of the RB coloration. To better observe the $\mathrm{RB}$ staining of protoplasm remains in the tests, the samples were resubmerged in a $50 \%$ ethanol solution in a Petri dish. Subsequently, the samples were investigated microscopically at a magnification of $64 \times$. Wellstained foraminiferal tests (i.e. all but the last (few) chambers stained vividly red or pink) of the different taxa were enumerated. These specimens were regarded as having been alive at the moment of harvesting.

Average living depth (ALD after Jorissen et al. 1995) of the taxa was calculated as follows:

$$
A L D_{X}=\sum_{i=1, x} \frac{n_{i} d_{i}}{N}
$$

where $x=$ depth of the deepest layer, $n_{i}=$ number of foraminifera of a species in the $i$ th sediment layer, $d_{i}$ is the depth midpoint of the $i$ th layer and $N$ is the total number of specimens in all layers. In this experiment, the ALDs were based on the top 6 sediment layers $(=3 \mathrm{~cm})$ in each branch.

Grain-size analyses were performed with the laser particle sizer Malvern Instruments Mastersizer S (see Stuut \& Prins 2001).

Taxonomic remarks. We followed the taxonomy described in Barmawidjaja et al. (1992), which was largely based on the taxonomy of Von Daniels (1970) and Jorissen (1987, 1988). Three species, however, have been renamed. Reophax scottii has now been assigned to the genus Leptohalysis. Reophax nana and Morulaeplecta bulbosa have been more appropriately described as Acostata mariae and Caronia silvestrii, respectively (see Brönnimann et al. 1992). Furthermore, some taxa have been lumped for practical reasons: juvenile individuals of Eggerella scabra and
Eggerella advena are difficult to distinguish. Therefore, both species were combined (Eggerella spp.). The taxa Bolivina seminuda, Bolivina dilatata and Bolivina spathulata are linked by numerous (quite abundant) intermediate forms (see Plate 2 in Barmawidjaja et al. 1992). It can be argued that these different forms should be distinguished on a sub-species level, as was also done for non-costate Bulimina morphotypes by Jorissen (1988). Because the similarity between the Bolivina morphotypes made a consistent division in the different 'species' problematic (especially for very small individuals), they are treated as 1 functional group (Bolivina spp.).

\section{RESULTS}

Fig. 2 displays the oxygen concentrations as measured during the experiment. In the aquarium, the oxygen content fluctuated between 4.05 and $4.78 \mathrm{ml} \mathrm{l}^{-1} \mathrm{O}_{2}$, whereas the $\left[\mathrm{O}_{2}\right]$ in the sealed microcosm branch
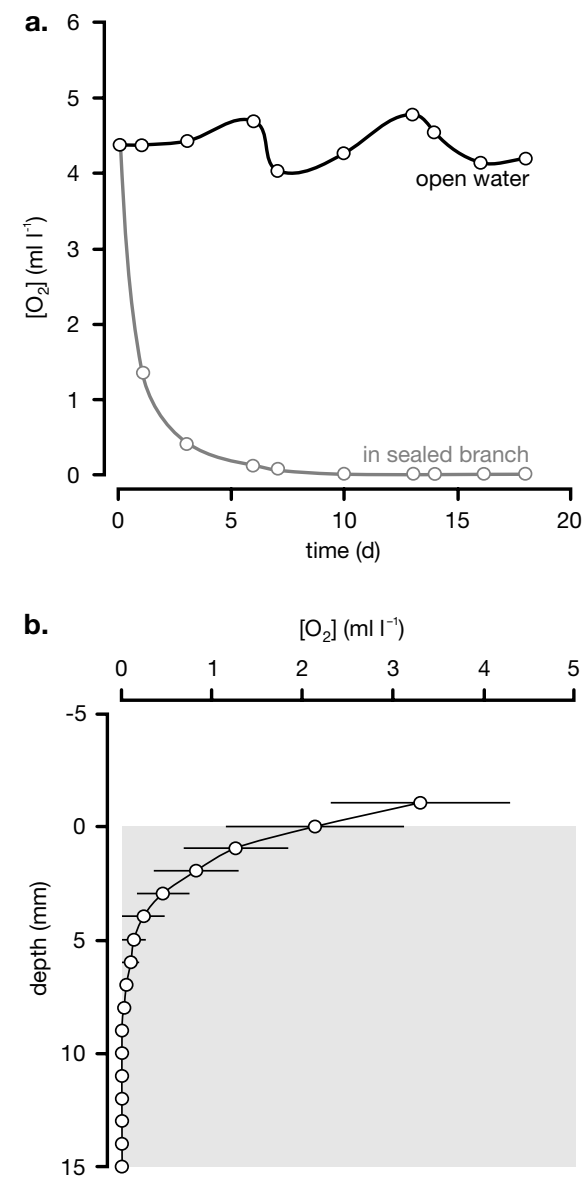

Fig. 2. Oxygen concentrations (a) in the water column of the open and sealed branch, and (b) in the sediment of the open branch $( \pm 1 \mathrm{SD}), 1 \mathrm{wk}$ after the beginning of the experiment 


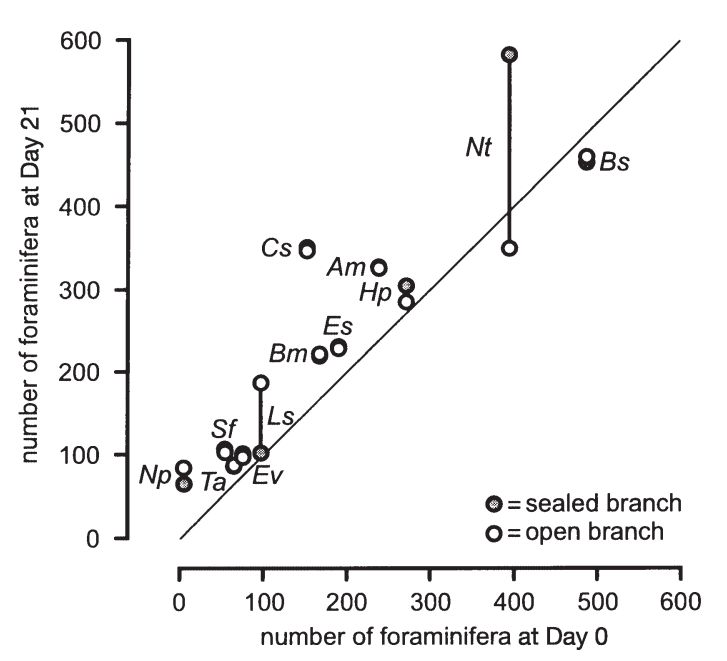

Fig. 3. Number of foraminifera in the sealed and open branches of the microcosm at the beginning versus at the end of the experiment. Abbreviations: $A m=$ Acostata mariae, $B m=$ Bulimina marginata, $B s=$ Bolivina spp., $C s=$ Caronia silvestrii, $E_{V}=$ Epistominella vitrea, $E s=$ Eggerella spp., $H p=$ Hopkinsina pacifica, Ls = Leptohalysis scottii, $N p=$ Nouria polymorphinoides, $N t=$ Nonionella turgida, $S f=$ Stainforthia fusiformis and Ta = Textularia agglutinans

dropped to 0 within Week 1 . In the open microcosm branch, the average penetration depth of detectable $\mathrm{O}_{2}$ levels was approximately $8 \mathrm{~mm}$.

The total numbers of the 12 most abundant taxa in both branches at Day 0 (at the beginning of the experiment) and Day 21 are shown in Fig. 3. For all species (except Bolivina spp. in both branches and Nonionella turgida in the open branch), the abundances were somewhat higher after 3 wk than at the beginning. Differences between total densities in the open and sealed branches after $3 \mathrm{wk}$ were not significant for all taxa (ANOVA, $F_{1,7}<0.96, \mathrm{p}>0.36$ ) except two. Only Nonionella turgida (ANOVA, $F_{1,7}=15.6, p=0.0075$ ) had more specimens in the sealed than the open branch. In contrast, Leptohalysis scottii (ANOVA, $F_{1,7}=5.25$, $\mathrm{p}=0.062$ ) had higher numbers in the open branch than in the sealed branch.

After $3 \mathrm{wk}$, the average living depths $\left(\mathrm{ALD}_{3}\right)$ revealed 2 distinct groups of foraminifera amongst the 12 most abundant species in our experiment (Fig. 4): Hopkinsina pacifica, Nouria polymorphinoides, Nonionella turgida, Stainforthia fusiformis, Leptohalysis scottii and Bolivina spp. are typical shallow-living taxa in our experiment; whereas Acostata mariae, Bulimina marginata, Caronia silvestrii, Epistominella vitrea, Textularia agglutinans and Eggerella spp. were members of a group of deeper dwelling species. The average $\mathrm{ALD}_{3}$ of all species was greater in the open branches than in the sealed ones. The differences in $\mathrm{ALD}_{3}$ were small for most species (especially in the deeper dwelling group:

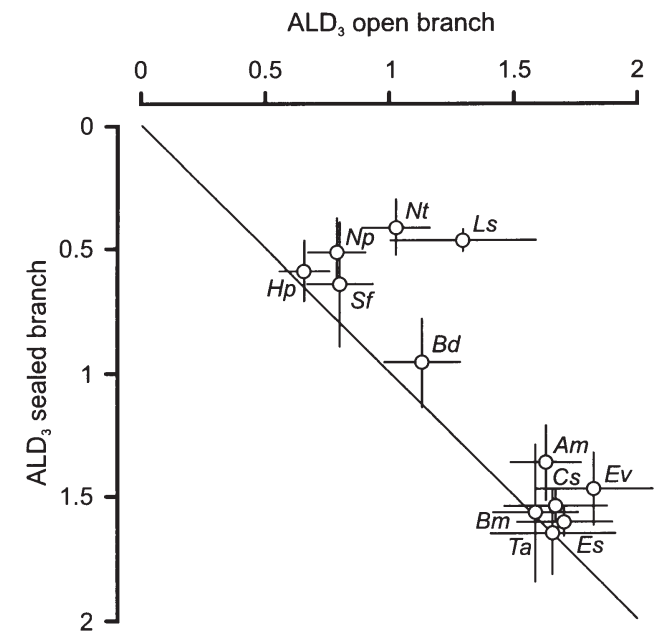

Fig. 4. Mean average living depths after $3 \mathrm{wk}\left(\mathrm{ALD}_{3}\right)$ of the most abundant taxa in the uppermost $3 \mathrm{~cm}$ of the open versus the sealed branch of the microcosm $( \pm 1$ SD). Species abbreviations as in Fig. 3

average difference $=0.15 \mathrm{~cm}$ ), they were very pronounced, however, for $N$. turgida $(0.61 \mathrm{~cm})$ and $L$. scottii $(0.83 \mathrm{~cm})$. For 5 species, the differences in $\mathrm{ALD}_{3}$ were significant (ANOVA): $N$. polymorphinoides $\left(F_{1,7}=8.65\right.$, $\mathrm{p}=0.026), N$. turgida $\left(F_{1,7}=46.9, \mathrm{p}=0.00048\right)$, L. scottii $\left(F_{1,7}=31.5, \mathrm{p}=0.0014\right), A$. mariae $\left(F_{1,7}=6.53, \mathrm{p}=0.043\right)$ and $E$. vitrea $\left(F_{1,7}=6.56, \mathrm{p}=0.043\right)$.

When we take a closer look at the vertical distribution of each of the species after $3 \mathrm{wk}$ (Fig. 5), it becomes clear that the group of deeper-living taxa (Fig. $5 \mathrm{~g}, \mathrm{~h}, \mathrm{i}, \mathrm{k}, \mathrm{l}$ ) was relatively evenly distributed throughout the sediment column. In some instances (especially in the open branch), they had a poorly developed subsurface maximum at about $2 \mathrm{~cm}$ depth. On the average, they seemed to be somewhat underrepresented in the top layer of the open branch, but apart from that there was no clear difference in vertical distribution between the branches.

In contrast, the more shallow-living species (Fig. 5a-f) had a very clear maximum in the top centimetres of the sediment. Notably in the sealed branch, these species were almost restricted to the top $5 \mathrm{~mm}$, whereas in the open branch, they also occurred at between 5 and $30 \mathrm{~mm}$ deeper in the sediment. Furthermore, in the open branch, most taxa (Nouria polymorphinoides, Nonionella turgida, Stainforthia fusiformis and Bolivina spp.) had their highest abundance in the second layer, between 5 and $10 \mathrm{~mm}$. They seemed to avoid the top $5 \mathrm{~mm}$ of the open branch, just like the deeper dwelling species. Only Hopkinsina pacifica reached maximum abundances in this surface layer.

The 6 more shallow dwelling taxa all showed significant differences in abundance with changing depth 


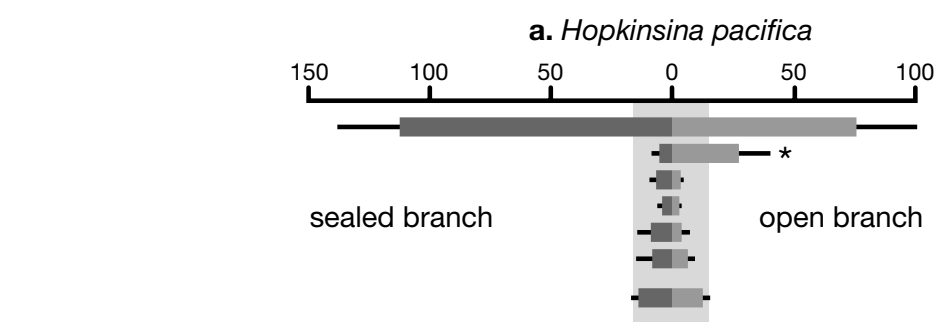

b. Nouria polymorphinoides

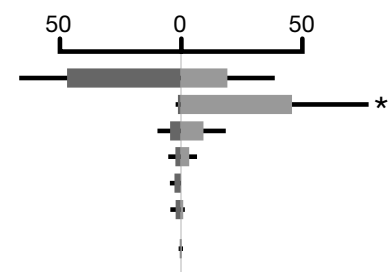

c. Nonionella turgida g. Acostata mariae

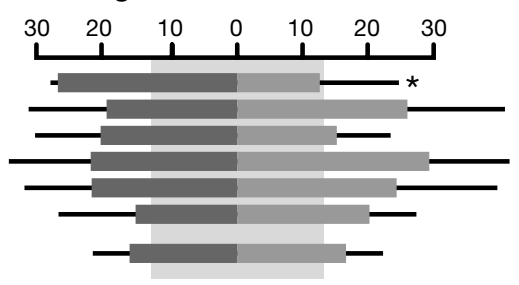

h. Bulimina marginata

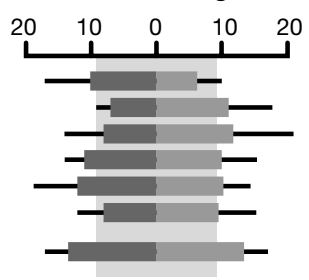

i. Caronia silvestrii

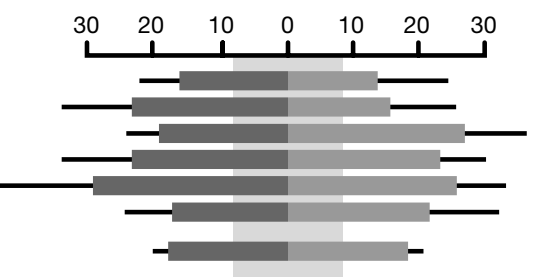

j. Epistominella vitrea

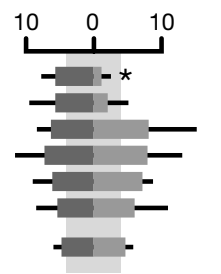

k. Textularia agglutinans

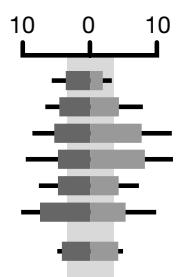

I. Eggerella scabra/advena

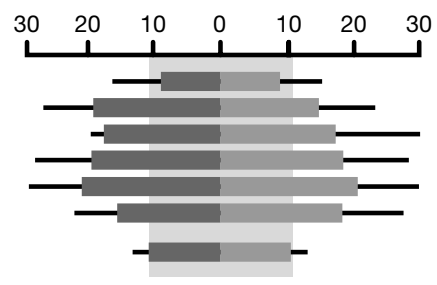

Fig. 5. Mean vertical distribution of foraminiferal species arranged in order of increasing average living depth. Bars on the left and the right give the numbers in the sealed and the open branch, respectively. The upper 6 bars indicate the foraminiferal abundance in $5 \mathrm{~mm}$ layers, the lowest bar gives abundances in the lower horizontal part of the microcosms. Abundances are given in numbers per layer volume $\left(=12.8 \mathrm{~cm}^{3}\right) \pm 1 \mathrm{SD}$. The light grey rectangle behind the bars shows the uniform distribution at Day 0 . Significance levels: ${ }^{*} p<0.05,{ }^{* *} p<0.01,{ }^{* * *} p<0.001$, indicating significant differences between corresponding sediment layers in open and sealed branches (ANOVA) 

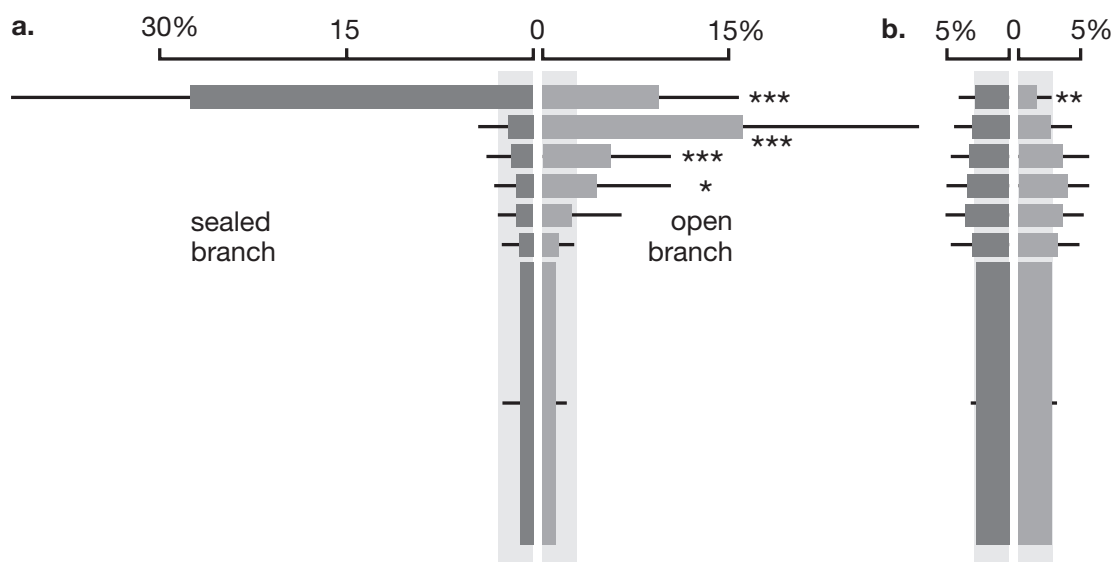

Fig. 6. Relative vertical distribution of (a) shallow and (b) deeper living species, expressed as percentage of the total number of individuals in the microcosm, averaged for all species in both groups $( \pm 1 \mathrm{SD})$. Bars on the left and the right give the vertical distribution in the sealed and the open branch, respectively. The upper 6 bars indicate the foraminiferal abundance in 5 mm layers, the lowest bar gives abundances in the lower horizontal part of the microcosms. The light grey rectangle behind the bars shows the uniform distribution at Day 0. Significance levels: ${ }^{*} p<0.05,{ }^{* *} p<0.01,{ }^{* * *} p<0.001$, indicating significant differences between corresponding sediment layers in open and sealed branches (ANOVA)

(ANOVA: for all taxa in the sealed branch, $F_{6,27}>7.82$, $\mathrm{p}<0.00017$; for all taxa in the open branch, $F_{6,27}>3.22$, $\mathrm{p}<0.021)$. For the deeper-living taxa, vertical differences were not significant (ANOVA: for all taxa in the sealed branch, $F_{6,27}<1.97, \mathrm{p}>0.11$; for all taxa in the open branch, $F_{6,27}<1.89$, p $>0.13$ ).

The performance of the 2 groups of species as a whole is summarized in Fig. 6, where the relative vertical distribution of the taxa was averaged. Here, we can see that for the shallow dwelling taxa, there is a significant difference in relative densities in the top $2 \mathrm{~cm}$ between corresponding depth intervals in the sealed and open branch. For the deeper dwellers, only the uppermost sediment layer shows a significant difference in relative density.

Table 1. Foraminiferal densities $\left(\mathrm{cm}^{-3}\right)$ in the sediment used for the experiment versus the field situation ( 0 to $2 \mathrm{~cm}$ sediment depth)

\begin{tabular}{|lcccr|}
\hline & $\begin{array}{c}\text { Experiment } \\
\text { (Day 0) }\end{array}$ & $\begin{array}{c}\text { Field } \\
\text { situation } \\
\text { Jan 1998 }\end{array}$ & $\begin{array}{c}\text { Field } \\
\text { situation } \\
\text { min. } \\
1996-98\end{array}$ & $\begin{array}{c}\text { Field } \\
\text { situation } \\
\text { max. } \\
1996-98\end{array}$ \\
\hline Bolivina spp. & 2.13 & 7.49 & 0.65 & 15.24 \\
Nonionella turgida & 1.72 & 4.45 & 0.93 & 39.19 \\
Hopkinsina pacifica & 1.18 & 3.54 & 0.24 & 3.54 \\
Acostata mariae & 1.04 & 1.63 & 1.08 & 11.39 \\
Eggerella spp. & 0.83 & 2.70 & 1.14 & 9.43 \\
Bulimina marginata & 0.73 & 0.31 & 0.01 & 1.61 \\
Caronia silvestrii & 0.66 & 2.30 & 0.35 & 3.35 \\
Leptohalysis scottii & 0.43 & 4.16 & 0.00 & 4.50 \\
Epistominella vitrea & 0.33 & 0.19 & 0.03 & 6.17 \\
Textularia agglutinans & 0.28 & 0.53 & 0.22 & 1.51 \\
Stainforthia fusiformis & 0.24 & 1.82 & 0.43 & 4.16 \\
Nouria polymorphinoides & 0.02 & 5.10 & 0.01 & 5.10 \\
\hline
\end{tabular}

\section{DISCUSSION}

\section{Experimental limitations and assumptions}

The sediment we used was taken from the seafloor using a Van Veen grabber. Unfortunately, this causes disturbance; especially the soft, foraminifer-rich top layer of the sediment was partially lost. This becomes clear when we compare foraminiferal abundances in the experiment with those in the upper $2 \mathrm{~cm}$ of a sediment core, obtained by SCUBA divers (Table 1). Shallow living taxa were underrepresented in the experiment, whereas 2 of the deeper dwellers (Bulimina marginata and Epistominella vitrea) were overrepresented. Because of the sieving and mixing prior to the experiment, the fragile agglutinated Nouria polymorphinoides and Leptohalysis scottii suffered huge losses. The differences between the experimental and field assemblages, however, are smaller than the huge annual variation in the field, shown by the minimum and maximum abundances found in sediment cores from 9 cruises in 1996, 1997 and 1998 (Duijnstee 2001).

The main assumption in this study is that initially foraminifera are equally distributed throughout the microcosms. To test this, 4 extra microcosms should have been filled and harvested immediately thereafter. This, however, would have doubled the number of samples, which was not feasible be- 
cause of time constraints. The problem is that the sediment (including foraminifera) may become sorted when the microcosms are filled. Therefore, the filling method was tested by performing grain-size analysis of the upper $5 \mathrm{~cm}$ of a filled microcosm (in $1 \mathrm{~cm}$ slices). The identical grain-size distributions revealed that sorting of sediment particles did not occur, suggesting that foraminiferal sediment particles were not sorted either. Since both branches of each microcosm were filled simultaneously in the same manner, we do not see how differences between the 2 treatments could have been induced by methods used at the beginning of the experiment.

For the experiment, a short 3 wk time interval was chosen to give foraminifera an opportunity to migrate, while limiting the effect of demographic processes. This was based on earlier experiments with sediment from the same locality (Duijnstee 2001).

\section{Migration versus demography}

To understand the vertical distributions observed in our experiment, we focus on 2 mechanisms that can explain deviations from the initial homogeneous distribution: migration and demography. Benthic foraminifera are clearly capable of vertical migration (e.g. Severin \& Erskian 1981, Weinberg 1990, Moodley et al. 1998b). Kitazato (1988) measured in-sediment velocities for foraminiferal species. Extrapolating these for the duration of our experiment would mean that Bolivina spp. could have travelled $50 \mathrm{~cm}$. For Nonionella stella (closely related to Nonionella turgida), this would be $57 \mathrm{~cm}$ and for Textularia spp. almost $1 \mathrm{~m}$. Similar values were observed by Wetmore (1988). The slowest of the 24 species she studied moved at a speed equivalent to $25 \mathrm{~cm}$ in $3 \mathrm{wk}$.

The second factor that could contribute to the vertical foraminiferal distribution is depth-dependent differences in demography. Prolonged exposure to high $\mathrm{H}_{2} \mathrm{~S}$ concentrations is lethal to many foraminifera (Moodley et al. 1998a). Hence, it is likely that in organic rich environments such as the northern Adriatic Sea, mortality is higher at greater, $\mathrm{H}_{2} \mathrm{~S}$-rich sediment depths. Fecundity may also be higher near the sediment surface than deeper under adverse redox conditions. Differential mortality and fecundity would lead to epifaunal patterns. In the present experiment, there was a population growth for some species (Nouria polymorphinoides, Stainforthia fusiformis and Caronia silvestrii in both branches, Nonionella turgida in the sealed branch and Leptohalysis scottii in the open branch). Thus, fecundity outweighed mortality and/or there was recruitment from the $<63 \mu \mathrm{m}$ size fraction. However, for all other species (and N. turgida in the open branch, and L. scottii in the sealed branch) total abundances after 3 wk were remarkably similar (Fig. 3) to the initial values (on the average 17\% higher). It does not seem very likely that their reproductive gains are almost precisely compensated by mortality. What is more probable is that the numbers of deaths and births were not very significant. We conclude that the distribution patterns are mainly due to migration.

\section{Why are shallow dwellers found at the sediment surface during anoxia?}

After $3 w k$, the shallow-dwelling species in the closed branch almost exclusively resided near the sediment surface. For a foraminiferal individual, this top layer was different from the deeper layers in 2 ways. First, this is where a positive redox state persisted longest (6 d, Fig. 2). Second, it was a boundary for upward migration.

One may assume that foraminifera migrate somewhere because they select optimal oxygen regimes (Alve \& Bernhard 1995). If so, this must have occurred within the first days of the experiment, because later on anoxia prevailed. The question then becomes why foraminifera stayed in this position for 2 more weeks, while the sediment surface was just as reduced as the sediment below.

The foraminifera may have migrated to the top layer in the first days, died in this position within the first week, but retained enough undecayed protoplasm at the end to stain red after treatment with RB. Sometimes tests contain residual protoplasm weeks after the foraminifera died (e.g. Bernhard 1988, 2000, Corliss \& Emerson 1990, Murray \& Bowser 2000). Therefore, using RB may be inaccurate. The decay time for protoplasm, however, is extremely variable, depending on environmental conditions and biovolume. Lutze \& Altenbach (1991) concluded that the RB method (used with great care) was wrong in only $4 \%$ of the 400 cases they tested. Duijnstee (2001) suggested that within $10 \mathrm{~d}$ decay of protoplasm in sediments from the northern Adriatic Sea leads to tests that can be readily recognized as non-living after staining with RB. Moreover, in an experiment with sediment from the same region, Moodley et al. (1997) observed living foraminifera of all major taxa (showing pseudopodial activity) after 11 wk of complete anoxia. Therefore, a scenario in which all shallow-living foraminifera in the sealed branch died in the beginning of our experiment (and were wrongfully regarded alive after $3 \mathrm{wk}$ ) seems unrealistic.

One could also argue that following the initial upward migration, there is no need for further migration 
since there is no detectable redox gradient to track. It is highly questionable, however, whether there was a clear upward redox gradient deep in the sediment at the very beginning of the experiment, because there is no 'direction' in consumption of oxygen or oxidized compounds deep in the freshly buried sediment, well below the oxygen penetration depth.

Perhaps the foraminifera were immobilized by the changing conditions that became chemically hostile. However, at the beginning of the experiment the rapidly deteriorating redox state deep in the sediment did not impede foraminiferal mobility, so, unless the effect is cumulative, why would it have this effect later on? Moreover, the augmented population size of Nonionella turgida (i.e. reproduction and growth to test sizes larger than $63 \mu \mathrm{m}$ ) could not be explained if the specimens are inactive for most of the experiment.

We suggest that the concentration of shallow-living foraminifera at the sediment surface in the anoxic branch was not merely a result of microhabitat selection during the first days, but that they were in a persistent state of negative geotaxis throughout the experiment. Therefore, the second characteristic of the top layer mentioned above (i.e. a dead end for upward migration) is, in our view, responsible for the observed pattern. Another indication of the existence of negative geotaxis can be found in the fact that there was no visible migration from one branch of the microcosm to the other. If benthic foraminifera are indeed capable of travelling long distances, as discussed earlier, one would expect species that prefer less reduced environments to appear in the top part of the open branch.

\section{Inducible negative geotaxis}

In the open branch, abundances of shallow-living taxa declined gradually from 5 to $20 \mathrm{~mm}$ sediment depth, whereas in the sealed branch, they were almost restricted to the uppermost sediment layer. An explanation for this could be that the negative geotaxis (that drove foraminifera persistently upward in the sealed branch) is triggered by an external stimulus such as high $\left[\mathrm{H}_{2} \mathrm{~S}\right]$. This would be an excellent adaptation to escape temporary environmental changes such as severe anoxia, since the sediment surface is the last microhabitat to turn chemically hostile and the first to be re-oxygenated. In the absence of this stimulus in the upper centimetres of the open branch, foraminiferal migration was not governed by negative geotaxis, but by 'normal' foraminiferal behaviour, controlled by the availability of or competition for food sources, as predicted by the TROX models (Jorissen et al. 1995, Van der Zwaan et al. 1999). Possible mechanisms for such 'normal' behaviour may include random migration, slowed down when specific food requirements are met.

The deeper-living species were remarkably evenly distributed through the sediment column. This vertical distribution (similar to the one at Day 0) could have been caused by inactivity due to stressful manipulations at the beginning of the experiment. The fact that populations of these species expanded, however, does not support this hypothesis. We conclude that the deeper dwellers showed no sign of clear negative geotaxis, and hardly any active microhabitat selection. This may have been caused by the fact that the required food source for these taxa was evenly distributed throughout the microcosm. If this food was abundant enough, the populations could thrive wherever they were initially located. Another possible explanation is that they either lack the ability for negative geotaxis or that they have a lower sensitivity for the stimulus. They are clearly tolerant, however, to the conditions deeper in the sediment, since they survived $3 \mathrm{wk}$ of burial. Caronia silvestrii and Acostata mariae even reproduced significantly under these circumstances (Fig. 3).

\section{Subsurface maximum}

The distribution of the shallow-living group in the open branch under almost natural oxygen conditions was different from the one in the anoxic branch. There was a clear subsurface maximum between 5 and $10 \mathrm{~mm}$ depths. Lower densities near the sediment surface could also be observed in the group of deeper-dwelling species. An explanation for this could be bioturbation by metazoans in the uppermost $3 \mathrm{~mm}$ of the open branch. Numerous burrows turned the top $3 \mathrm{~mm}$ into a fluffy layer. This layer was absent in the sealed branch, probably due to high meiofaunal mortality. Bioturbation may be an important factor in the development of subsurface maxima (e.g. Lipps 1983, Moodley 1990, Moodley et al. 1998b), transporting foraminifera back into the sediment. It seems unlikely, however, that predation by metazoans is an important factor because of the similarity in foraminiferal numbers between the start and end of our experiment, and also between both branches. We estimate that 30 to $40 \%$ of the fluffy layer consisted of burrows instead of sediment and the sediment itself had a high water content. The result is a decreased volume of habitable substrate and lower foraminiferal densities.

Of all taxa, only Hopkinsina pacifica was most abundant in the top layer of both branches. The same was observed in experiments with sediment from the same location (Ernst et al. 2002). An explanation for this could be an ability of the species for 'true' epifaunal 
behaviour (i.e. living at the watery side of the sediment water interface); it would therefore profit from the increase of surface area caused by the burrows.

\section{CONCLUSIONS}

Under conditions of experimental bottom-water anoxia, typical shallow living foraminiferal taxa reside almost exclusively in the top $5 \mathrm{~mm}$ of the sediment, whereas they live deeper in the sediment (and reach a density maximum between 5 and $10 \mathrm{~mm}$ ) when the bottom-water is oxygenated. The patterns in vertical distribution of the foraminifera in the experiment were the result of foraminiferal migration, rather than differential mortality or reproduction. The shallow living depths under anoxic bottom-water conditions are most probably caused by a persisting state of negative geotaxis induced by some external stimulus associated with a certain redox state of the sediment (perhaps high $\left[\mathrm{H}_{2} \mathrm{~S}\right]$ ). Deeper-dwelling species do not show any sign of negative geotaxis in the experiment. They may either lack the ability for it or are less sensitive to the stimulus.

Acknowledgements. The authors wish to thank the crew of RV 'Vila Velebita' and staff from the Ruđer Bošković Institute (Center for Marine Research in Rovinj, Croatia) for collecting the sediment. Gerrit van't Veld and Geert Ittmann are acknowledged for processing the samples. This research was supported by the Netherlands Council for Earth and Life Sciences (ALW), with financial aid from the Netherlands Organization for Scientific Research (NWO).

\section{LITERATURE CITED}

Alve E, Bernhard JM (1995) Vertical migratory response of benthic foraminifera to controlled oxygen concentrations in an experimental mesocosm. Mar Ecol Prog Ser 116: $137-151$

Barmawidjaja DM, Jorissen FJ, PuškarićS, Van der Zwaan GJ (1992) Microhabitat selection by benthic foraminifera in the northern Adriatic Sea. J Foraminiferal Res 22:297-317

Bernhard JM (1988) Postmortem vital staining in benthic foraminifera: duration and importance in population and distributional studies. J Foraminifer Res 18:143-146

Bernhard JM (2000) Distinguishing live from dead foraminifera: methods review and proper applications. Micropaleontology 46:38-46

Brönnimann P, Whittaker JE, Valleri G (1992) Agglutinated foraminifera from the Lagoon of Venice, Italy. Rev Paleobiol 11:97-109

Buzas MA (1965) The distribution and abundance of foraminifera in Long Island Sound. Smithson Misc Collect 149: $1-89$

Buzas MA, Culver SJ, Jorissen FJ (1993) A statistical evaluation of the microhabitats of living (stained) infaunal benthic foraminifera. Mar Micropaleontol 20:311-320

Corliss BH (1985) Microhabitats of benthic foraminifera within deep-sea sediments. Nature 314:435-438
Corliss BH, Emerson S (1990) Distribution of rose-bengal stained deep-sea benthic foraminifera from the Nova Scotian continental margin and Gulf of Maine. Deep-Sea Res I $37: 381-400$

Degobbis D (1989) Increased eutrophication of the northern Adriatic Sea. Second act. Mar Pollut Bull 20:452-457

Duijnstee IAP (2001) Experimental ecology of foraminifera. Towards better quantitative paleoecological reconstructions. PhD thesis, Institute of Earth Sciences, Utrecht University, The Netherlands

Ernst SR, Duijnstee IAP, Van der Zwaan GJ (2002) The dynamics of the benthic foraminiferal microhabitat: recovery after experimental disturbance. Mar Micropaleontol 46:343-361

Grossman EL (1984a) Carbon isotopic fractionation in live benthic foraminifera-comparison with inorganic precipitate studies. Geochim Cosmochim Acta 48:1505-1512

Grossman EL (1984b) Stable Isotope fractionation in live benthic foraminifera from the Southern California Borderlands. Paleogeogr Paleoclimatol Paleoecol 47:301-327

Jorissen FJ (1987) The distribution of benthic foraminifera in the Adriatic Sea. Mar Micropaleontol 12:21-48

Jorissen FJ (1988) Benthic foraminifera from the Adriatic Sea: principles of phenotypic variation. Utrecht Micropaleontol Bull 37:174

Jorissen FJ (1999) Benthic foraminiferal microhabitats below the sediment-water interface. In: Sen Gupta BK (ed) Modern foraminifera. Kluwer Academic Publishers, Dordrecht, p 161-179

Jorissen FJ, De Stigter HC, Widmark JGV (1995) A conceptual model explaining benthic foraminiferal microhabitats. Mar Micropaleontol 22:3-15

Jorissen FJ, Wittling I, Peypouquet JP, Rabouille C, Relexans JC (1998) Live benthic foraminiferal faunas off Cape Blanc, NW-Africa: community structure and microhabitats. Deep-Sea Res I 45:2157-2188

Justić D (1987) Long-term eutrophication of the northern Adriatic Sea. Mar Pollut Bull 18:281-284

Justić D (1991) Hypoxic conditions in the northern Adriatic Sea: historical development and ecological significance. In: Tyson RV, Pearson TH (eds) Modern and ancient continental shelf anoxia. Geol Soc Spec Publ 58:95-105

Kitazato H (1988) Locomotion of some benthic foraminifera in and on sediments. J Foraminifer Res 18:344-349

Linke P, Lutze GF (1993) Microhabitat preferences of benthic foraminifera - a static concept or a dynamic adaptation to optimize food acquisition? Mar Micropaleontol 20:215-234

Lipps JH (1983) Biotic interactions in benthic foraminifera. In: Tevesz MJS, McCall PJ (eds) Biotic interactions in recent and fossil benthic communities. Plenum Press, New York, p 331-376

Lutze GF, Altenbach A (1991) Technik und Signifikanz der Lebendfärbung benthischer Foraminiferen mit Bengalrot. Geol Jahrb Reihe A 128:251-265

Mackensen A, Douglas RG (1989) Down-core distribution of live and dead deep-water benthic foraminifera in box cores from the Weddell Sea and the California continental borderland. Deep-Sea Res I 36:879-900

McCorkle DC, Keigwin LD, Corliss BH, Emerson SR (1990) The influence of microhabitats on the carbon isotopic composition of deep-sea benthic foraminifera. Paleoceanography 5:161-185

Moodley L (1990) Southern North Sea seafloor and substrate distribution of living benthic foraminifera. Neth J Sea Res 27:57-71

Moodley L, Van der Zwaan GJ, Herman PMJ, Kempers L, Van Breugel P (1997) Differential response of benthic 
meiofauna to anoxia with special reference to Foraminifera (Protista: Sarcodina). Mar Ecol Prog Ser 158:151-163 Moodley L, Schaub BEM, Van der Zwaan GJ, Herman PMJ (1998a) Tolerance of benthic foraminifera (Protista: Sarcodina) to hydrogen sulphide. Mar Ecol Prog Ser 169:77-86

Moodley L, Van der Zwaan GJ, Rutten GMW, Boom RCE, Kempers AJ (1998b) Subsurface activity of benthic foraminifera in relation to porewater oxygen content: laboratory experiments. Mar Micropaleontol 34:91-106

Murray JW (1991) Ecology and paleoecology of benthic foraminifera. Longman Scientific \& Technical, Harlow, p 398

Murray JW, Bowser SS (2000) Mortality, protoplasm decay rate, and reliability of staining techniques to recognize 'living' foraminifera: a review. J Foraminifer Res 30:66-70

Richter G (1961) Beobachtungen zur Ökologie einiger Foraminiferen des Jade-Gebietes. Natur Volk (Frankf) 91: $163-170$

Severin KP, Erskian MG (1981) Laboratory experiments on the vertical movement of Quinqueloculina impressa Reuss through sand. J Foraminifer Res 11:133-136

Stuut JBW, Prins MA (2001) Precision, accuracy and resolution of the laser particle sizer Malvern Mastersizer S and unmixing of artificial sediment mixtures. In: Stuut JBW (ed) Late Quaternary Southwestern African terrestrial-

Editorial responsibility: Lisa Levin (Contributing Editor), La Jolla, California, USA climate signals in the marine record of Walvis Ridge, SE Atlantic Ocean. Geologica Ultraiectina 212:35-52

Van der Zwaan GJ, Jorissen FJ (1991) Biofacial patterns in river-induced shelf anoxia. In: Tyson RV, Pearson TH (eds) Modern and ancient continental shelf anoxia. Geol Soc Spec Publ 58:65-82

Van der Zwaan GJ, Duijnstee IAP, Den Dulk M, Ernst SR, Jannink NT, Kouwenhoven TJ (1999) Benthic foraminifers: proxies or problems? A review of paleoecological concepts. Earth Sci Rev 46:213-236

Von Daniels CHE (1970) Quantitative ökologische Analyse der zeitlichen und räumlichen Verteilung rezenter Foraminiferen im Limskikanal bei Rovinj (nördliche Adria). Gött Arb Geol Paläontol 8:1-144

Walton WR (1952) Techniques for recognition of living Foraminifera. Contrib Cushman Found Foraminifer Res 3:56-60

Weinberg JR (1990) High rates of long-term survival of deepsea infauna in the laboratory. Deep-Sea Res I 37:1375-1379

Wetmore KL (1988) Burrowing and sediment movement by benthic foraminifera, as shown by time-lapse cinematography. Rev Paleobiol Spec Publ 2:921-927

Woodruff F, Savin SM, Douglas RG (1980) Biological fractionation of oxygen and carbon isotopes by recent benthic foraminifera. Mar Micropaleontol 5:3-11

Submitted: August 28, 2001; Accepted: July 19, 2002

Proofs received from author(s): December 17, 2002 